\title{
HIV-2 gene product-specific $T$ cell responses and viraemia control
} Aleksandra Leligdowicz*1,2, Louis-Marie Yindom ${ }^{1}$, Assan Jaye1, Tao Dong2, Abraham Alabi ${ }^{1}$, Ramu Sarge-N'jie ${ }^{1}$, Harr Njai ${ }^{1}$, Andrew McMichael ${ }^{2}$, Hilton Whittle ${ }^{1}$ and Sarah Rowland-Jones ${ }^{1,2}$

\author{
Address: ${ }^{1}$ Medical Research Council Laboratories, Fajara, The Gambia and ${ }^{2}$ Medical Research Council Human Immunology Unit, Weatherall \\ Institute of Molecular Medicine, Oxford, UK \\ * Corresponding author
}

from 2006 International Meeting of The Institute of Human Virology

Baltimore, USA. 17-2I November, 2006

Published: 21 December 2006

Retrovirology 2006, 3(SuppI I):S35 doi:10.1 186/1742-4690-3-SI-S35

(c) 2006 Leligdowicz et al; licensee BioMed Central Ltd.

\section{Background}

HIV-2 infection is characterized by an attenuated disease course in most patients, which may reflect viraemia control by an efficient immune response. However, there is little information on the breadth, magnitude, or specificity of cellular immune responses to the proteome and their relationship to viral control.

\section{Methods}

105 freshly separated PBMCs from 64 members of a welldescribed community-based HIV-2 cohort (Caio, Guinea Bissau) were used in ex vivo IFNg ELISpot assays. 424 peptides spanning the HIV-2 proteome were divided into $3 \times$ 24 pools in a 3-dimensional matrix (16-20 peptides/ pool, $2 \mu \mathrm{g} / \mathrm{ml}$ per peptide).

\section{Results}

All HIV-2 gene products induced IFNg responses, with Gag being targeted most frequently ( $89 \%$ of patients). The total proteome response inversely correlated with HIV-2 VL $(\mathrm{p}<0.01)$ and this relationsAhip was due to targeting Gag $(\mathrm{p}<0.01)$. Patients with $\mathrm{VL} \leq 100(\mathrm{~N}=31)$ had a greater median gag-specific response (1120 vs 385 SFU, p $<0.01)$ than patients with $\mathrm{VL} \geq 100(\mathrm{~N}=33)$. Responses to a single Gag peptide (recognized by $>30 \%$ of patients) correlated with low VL $(\mathrm{p}=0.05)$.

\section{Conclusion}

There is a strong relationship between HIV-2 VL and IFNg responses. VL $\leq 100$ correlates with targeting Gag, with the 6 most frequently recognized peptides originating from a highly conserved region spanning 149 aa, suggesting that immune responses to this region play a role in HIV-2 viraemia control. 